\title{
MICROPROPAGACIÓN DE Salix spp. A TRAVÉS DE MERISTEMAS FOLIARES
}

\section{PATRICIO CHUNG G. y BASILIO CARRASCO G.}

Instituto Forestal de Chile.

\section{RESUMEN}

En este artículo se detallan los procedimientos empleados en la micropropagación de meristemas foliares de 25 procedencias de Salix spp. Se probaron diferentes protocolos de desinfección del material vegetal, dando los mejores resultados la aplicación alternada de una mezcla de fungicidas (Benlate y Captan) y una solución de cloro comercial al $10 \%$ por 20 minutos.

El medio de cultivo utilizado en el proceso de multiplicación fue una modificación de Murashige y Skoog (1962). Las hormonas aplicadas para la multiplicación y enraizamiento de los explantes fueron benziladenina (BA) y ácido giberélico (GA3), siendo 0,1 mg de BA y 1,0 mg de GA3 las concentraciones más efectivas.

En la etapa de aclimatación, el sustrato con mejores resultados fue la mezcla en partes iguales de arena de Lampa y Sunshine M16 5 Plug, alcanzando una sobrevivencia mayor al 80 $\%$. Esta tecnología fue una medida eficaz y rápida para sanear material vegetal valioso con problemas cuarentenarios.

Palabras Claves: Salix spp., micropropagación, meristemas foliares, multiplicación, aclimatación.

\section{ABSTRACT}

In this article we detail the procedures used for the micropropagation of foliate meristems in 25 provenances of Salix spp. Are detailed different protocols of chemical disinfection of the vegetal material were tested; the best results were obtained by alternate applications of a mixture of fungicides (Benlate and Captan) and a solution of commercial chlorine at 10\% for 20 minutes.

A culture medium modified from Murashige y Skoog (1962) was used. The vegetable hormones applied for rooting and multiplication of the explants were benzyladenine (BA) and gibberelic acid (GA3), the most effective concentrations were $0.1 \mathrm{mg} /$ of $B A$ and $1.0 \mathrm{mg} / \mathrm{l}$ of GA3.

In the acclimatization stage, the substrate with best results was the mixture of equal parts of "Lampa sand" and Sunshine M16 5 Plug, which produced a survival of more than $80 \%$. This technology was an appropriate tool for cleaning available vegetal material with quarantine problems.

Keywords: Salix spp., Micropropagation, foliate meristems, multiplication, acclimatization. 


\section{INTRODUCCIÓN}

El cultivo de muchas de las especies del género Salix ha aumentado considerablemente en las últimas décadas en Europa y Estados Unidos debido, fundamentalmente, a su gran versatilidad de usos, su reconocida alta producción de biomasa, elevada tasa de crecimiento, facilidad de establecimiento y resistencia a heladas (Stoehr et al , 1989).

Sin embargo, en Chile la utilización comercial de especies del género Salix es todavía muy restringida pues, su única especie nativa (Salix humboldtiana) no tiene una aplicación conocida y las pequeñas áreas cultivadas son monoespecíficas (Salix viminalis), y se han especializado sólo en la producción de varas para la fabricación de artesanía.

Para superar estas restricciones y potenciar el cultivo de Salix, el Instituto Forestal (INFOR) dentro de sus proyectos de diversificación forestal, introdujo desde Suecia una partida de 25 procedencias. En dicha partida, el Servicio Agrícola y Ganadero (SAG) detectó la presencia de un hongo cuarentenario (Diplodina microsperma) y por lo tanto, determinó la eliminación preventiva de todas las plantas. Por consiguiente, se procedió a desarrollar un programa de micropropagación, destinado al saneamiento de dicho material vegetal.

$\mathrm{Al}$ respecto, la micropropagación de meristemas foliares es en la actualidad una metodología ampliamente utilizada a nivel mundial para la multiplicación clonal de especies forestales (Dhawan,1993). La exitosa aplicación de esta tecnología se debe, fundamentalmente, a su facilidad técnica y rápida obtención de un gran número de plantas clonales, en una pequeña superficie y en cualquier época del año (Espejo et al, 1990). Además, permite obtener plantas libres de organismos fitopatógenos, lo que la hace una alternativa muy interesante para mantener y multiplicar masivamente especies valiosas que presenten algún problema sanitario, como es el caso de las especies de Salix introducidas al país por INFOR.

\section{OBJETIVOS}

1) El rescate de 25 procedencias de Salix spp. con problemas cuarentenarios, por medio de las técnicas del cultivo de tejidos.

2) Obtener los protocolos de desinfección, multiplicación, enraizamiento y aclimatación para cada una de las procedencias. 


\section{MATERIALES Y MÉTODOS}

\section{Material Vegetal}

En el programa de micropropagación se utilizaron 25 procedencias de Salix spp. introducidas desde la Facultad de Ciencias Agrícolas de la Universidad de Uppsala , Suecia. La identificación de cada procedencia se detalla en el Cuadro 1.

Cuadro 1.

IDENTIFICACIÓN DE LAS ESPECIES Y PROCEDENCIAS DE Salix spp. UTILIZADAS EN EL PROGRAMA DE MICROPROPAGACIÓN.

\begin{tabular}{|l|l|}
\hline Especies & Identificación de las Procedencias \\
\hline S.stipularis(hib) & UK \\
\hline Salix viminalis & UK BOWLES HIBRID \\
\hline Salix viminalis & UK MULATIN \\
\hline Salix viminalis & UK 445 DE BIARDII \\
\hline Salix viminalis & SWE 78183 \\
\hline Salix viminalis & SWE 79046 \\
\hline Salix viminalis & SWE 78112 \\
\hline Salix triandra & UK Black Maul \\
\hline Salix purpurea & CAN ONTARIO PUR12 \\
\hline Hibrido China shrub & CAN. ONTARIO S-67 \\
\hline Hibrido Belgicum Red & HOLANDA \\
\hline Salix dasyclados & UK \\
\hline Salix dasyclados & SWE 77056 \\
\hline Salix dasyclados & SWE 79097 \\
\hline Salix dasyclados & SWE 81090 \\
\hline Salix burjatica & UK KORSO \\
\hline Salix burjatica & UK GERMANY \\
\hline Salix burjatica & UK-83 \\
\hline Salix calodendron & UK \\
\hline Salix sericans & UK COLES \\
\hline Salix sericans & UK REIFENWEIDE \\
\hline Salix eriocephala & CAN.ONTARIO 558 \\
\hline Salix eriocephala & CAN. ONTARIO ER63 \\
\hline $\begin{array}{l}\text { S.eriocephala } x \\
\text { pentandra }\end{array}$ & CAN. ONTARIO 601 \\
\hline S.eriocephala $x$ exigua & CAN. ONTARIO 611 \\
\hline
\end{tabular}

\section{Medio de Cultivo}

Tomando como base el medio nutritivo (MS) desarrollado por Murashige y Skoog (1962) para plantas de tabaco, se probaron 3 diluciones $(100 \%, 50 \%, 25 \%)$ del medio basal, presencia o ausencia de benziladenina (BA) y 3 concentraciones de ácido giberélico $\left(\mathrm{GA}_{3}\right)$. La composición química del medio MS se muestra en el Cuadro 2. 
Cuadro 2.

COMPOSICIÓN DEL MEDIO DE CULTIVO UTILIZADO EN EL PROCESO DE MICROPROPAGACIÓN DE 25 PROCEDENCIAS DE Salix spp.

\begin{tabular}{|lc|}
\hline Macronutrientes & Concentración \\
$\mathrm{KH}_{2} \mathrm{PO}_{4}$ & $170 \mathrm{mg}$ \\
$\mathrm{N}_{2} \mathrm{H}_{4} \mathrm{O}_{3}$ & $1.650 \mathrm{mg}$ \\
$\mathrm{Ca} \mathrm{Cl}_{2} \times 2 \mathrm{H}_{2} \mathrm{O}$ & $440 \mathrm{mg}$ \\
$\mathrm{Mg} \mathrm{SO}_{4} \times 7 \mathrm{H}_{2} \mathrm{O}$ & $370 \mathrm{mg}$ \\
$\mathrm{KNO}_{3}$ & $1.900 \mathrm{mg}$ \\
\hline Micronutrientes & Concentración \\
Molibdato de Sodio & $0,25 \mathrm{mg}$ \\
Sulfato Cúprico & $0,025 \mathrm{mg}$ \\
Sulfato de Manganeso & $22,3 \mathrm{mg}$ \\
Sulfato de Zinc & $8,6 \mathrm{mg}$ \\
Cloruro de Cobalto & $0,025 \mathrm{mg}$ \\
Ácido Bórico & $6,2 \mathrm{mg}$ \\
Sulfato Ferroso & $27,95 \mathrm{mg}$ \\
EDTA & $37,2 \mathrm{mg}$ \\
\hline Vitaminas & Concentración \\
Tiamina & $0,25 \mathrm{mg}$ \\
Piridoxina & $0,25 \mathrm{mg}$ \\
Ácido Nicotínico & $0,25 \mathrm{mg}$ \\
\hline Otros & Concentración \\
Azúcar & $20,0 \mathrm{gr}$ \\
Agar & $7,0 \mathrm{gr}$ \\
PH & 5,7 \\
\hline
\end{tabular}

\section{Proceso de Micropropagación}

El proceso de micropropagación fue llevado a cabo en tres etapas: desinfección del material vegetal, multiplicación y aclimatación.

\section{Desinfección del Material Vegetal}

En una cámara de flujo laminar, ramillas de Salix spp. con aproximadamente 15 brotes, fueron sumergidas en una mezcla de fungicidas (Benlate $200 \mathrm{mg} / \mathrm{lt}$; Captan 200 $\mathrm{mg} / \mathrm{tt}$ ) por 30 minutos y tratadas con una solución de hipoclorito de sodio al $10 \%$ por períodos de 10, 20, 30 y 40 minutos. Luego, los trozos fueron lavados 3 veces con agua destilada estéril. Finalmente, las ramillas se dividieron tratando de dejar un par de meristemas foliares por corte.

Multiplicación

Cada trozo desinfectado fue introducido en frascos con medio de cultivo MS para inducir el desarrollo de brotes foliares. Al cabo de 5 semanas, los frascos con abundantes brotes fueron seleccionados para su multiplicación. 
En el proceso de multiplicación, los explantes fueron divididos y nuevamente fueron cultivados en medio MS. Este procedimiento fue realizado hasta obtener 500 explantes para cada procedencia.

Durante toda la etapa de multiplicación, los explantes se mantuvieron en una sala con temperaturas que fluctuaron entre los $21^{\circ} \mathrm{C}$ y $22^{\circ} \mathrm{C}$ y 16 horas de luz artificial $\left(40 \mathrm{uE} / \mathrm{m}^{2} \mathrm{~s}\right)$.

Aclimatación

Los explantes que mostraron un adecuado desarrollo de raíces y follaje fueron sometidos al proceso de aclimatación. Para ello, las plantas se extrajeron cuidadosamente de los frascos, y con abundante agua se eliminaron los restos de medio adheridos a las raíces para evitar la proliferación de hongos.

Posteriormente, los explantes fueron transplantados a cubetas plásticas estériles $(33 \mathrm{~cm} \times 20 \mathrm{~cm} \times 10 \mathrm{~cm})$ con aproximadamente $3.300 \mathrm{~cm}^{3}$ de sustrato húmedo estéril. Se probaron tres tipos de sustrato: arena, vermiculita y una mezcla en partes iguales de arena de Lampa y mezcla Sunshine M16 5 Plug (70-80\% turba canadiense esfagnacea, perlita fina, dolomita, yeso agrícola y agentes humectantes).

Finalmente, las cubetas fueron selladas con plástico (alusaplast) y se mantuvieron en una sala a $22^{\circ} \mathrm{C}$ y 16 horas de luz $\left(40 \mathrm{uE} / \mathrm{m}^{2} \mathrm{~s}\right)$. Al cabo de 7 días comenzaron las aplicaciones de riego, fungicidas y fertilizante (MS al 50\%). Cuando se verificó que las plantas respondían al sustrato, gradualmente fueron expuestas al medio ambiente externo, antes de llevarlas al invernadero.

\section{Monitoreo de las Condiciones Fitosanitarias.}

Durante todas las etapas de la micropropagación de Salix spp. se monitoreó la presencia de organismos fitopatógenos, cuya identificación fue llevada a cabo en los laboratorios del Servicio Agrícola y Ganadero.

\section{RESULTADOS Y DISCUSIÓN}

\section{Efecto de la Desinfección del Material Vegetal}

El tratamiento de desinfección que permitió mantener niveles de asepcia mayores al $70 \%$, fue sumergir las ramillas en una mezcla de fungicidas y Hipoclorito de sodio al $10 \%$ por 30 y 20 minutos respectivamente. El uso de cloro comercial por un período superior a 30 minutos indujo necrosis de los tejidos en todas las procedencias estudiadas. 


\section{Efecto de Diferentes Concentraciones de Nutrientes en el Medio Basal}

Para todos los medios de cultivo se mantuvo la misma composición química basal detallada en la tabla 2 , sólo se modificaron las concentraciones de los nutrientes en el medio $(100 \%, 50 \%$ y $25 \%)$.

Después de una serie de ensayos, se pudo determinar que las concentraciones de nutrientes al $100 \%$ y $50 \%$ mostraron un mejor desarrollo de los explantes, existiendo escasa diferencia entre ellas. Por lo tanto, la concentración al 50\% se mantuvo durante todo el desarrollo del programa de micropropagación.

\section{Efecto de los Reguladores de Crecimiento}

Se emplearon 3 dosis de $\mathrm{GA}_{3}(0,1,0,5$ y $1,0 \mathrm{mg} / \mathrm{tt}$ de medio de cultivo) en presencia o ausencia de BA $(0,1 \mathrm{mg})$ y BA solo. Después de una serie de experimentos preliminares, se determinó que los mejores tratamientos eran $1,0 \mathrm{mg}$ de $\mathrm{GA}_{3}, 0,1 \mathrm{mg}$ de BA y la combinación de ambas concentraciones hormonales. Tales resultados permitieron diferenciar las siguientes etapas en el proceso de multiplicación, inducción de brotes, elongación de brotes y desarrollo de raíces.

\section{Inducción de Brotes}

La inducción de brotes varió según la procedencia y la hormona aplicada. Como se puede apreciar en el Cuadro 3, el $60 \%$ de las procedencias estudiadas indujo brotes al aplicar $0,1 \mathrm{mg}$ de BA al medio basal. Al cabo de 4 a 5 semanas mostraban 2 a 8 brotes foliares de 5 a $10 \mathrm{~mm}$ de largo ( un ejemplo se muestra en la Figura 1).

De todas las procedencias que desarrollaron brotes en presencia de BA, sólo Salix triandra procedencia UK Black Maul, dio origen a una masa amorfa de hojas quebradizas (vitrificación). Este desorden fisiológico ha sido reportado en Salix babylonica, siendo atribuido a la aplicación de citoquininas como BA al medio basal (Gaspar et al, 1987).

En la mayoría de las investigaciones sobre micropropagación de especies forestales se señala que BA estimula el crecimiento de brotes foliares (Wolter, 1970; Winton, 1968; Bergman et al, 1992; Ahuja, 1987; Minicha, 1987). Al respecto, estudios realizados en diferentes clones de Salix spp. (Bergman et al, 1984;1992), en S. exigua (Stoehr et al,1989) y en el híbrido $S$. matsudana $x$ alba (Bhojwani, 1980), demuestran que la aplicación de $0,1 \mathrm{mg} / \mathrm{lt}$ de BA estimula la proliferación de aproximadamente 2 a 4 brotes por explante.

Similares resultados han sido descritos por Agrawal y Gebhardt (1994), para el híbrido $S$. fragilis $x$ lispoclados, en el que la aplicación de $0,2 \mathrm{mg} / \mathrm{lt}$ de BA aumentó en 5 
veces la proliferación de brotes. Pope et al, (1990), obtuvo una respuesta similar en $S$. gooddingii pero utilizando una mayor concentración de BA $(0,4 \mathrm{mg} / \mathrm{lt})$.

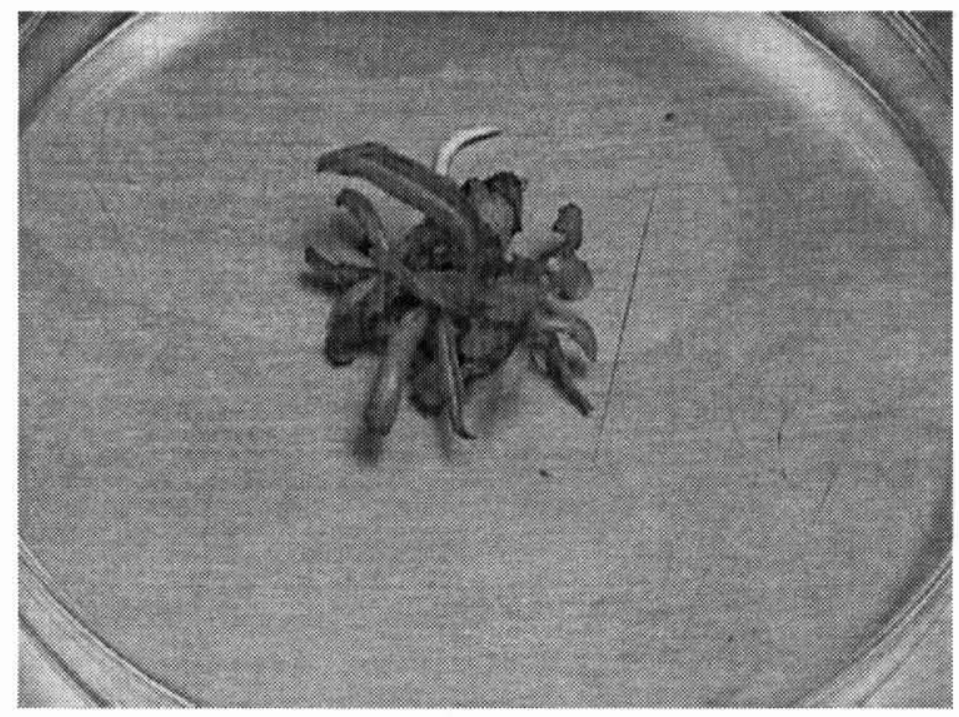

Figura 1. DESARROLLO DE Salix burjatica,(PROCEDENCIA UK GERMANY) EN MEDIO MS MÁS 0,1 MG DE BA.

Por otro lado, un $28 \%$ de las procedencias desarrolló brotes cuando se aplicó al medio $0,1 \mathrm{mg}$ de BA más $1,0 \mathrm{mg}$ de $\mathrm{GA}_{3}$, y sólo un $12 \%$ lo hizo en presencia de $1,0 \mathrm{mg}$ de $\mathrm{GA}_{3}$.

$\mathrm{Al}$ analizar más detalladamente la tabla 3, se puede observar que existieron algunas diferencias intraespecíficas en la inducción de brotes. Es así como en $\boldsymbol{S}$. viminalis, la procedencia UK445 DE BIARDII desarrolló un número óptimo de brotes en presencia de BA más $\mathrm{GA}_{3}$ (Figura 2). En $\boldsymbol{S}$. dasyclados, la procedencia UK fue la única que respondió a BA. Mientras que cada una de las 3 procedencias de $S$. burjatica respondió a un tratamiento hormonal específico.

Elongación de brotes

La elongación de brotes fue afectada principalmente por el tratamiento hormonal y la procedencia. Es así como las procedencias que presentaban una buena producción de brotes en presencia de BA, tuvieron a su vez una deficiente elongación de ellos (ejemplos se muestran en la Figura 1 y Figura 2, columna D). 
Cuando se aplicó sólo $\mathrm{GA}_{3}$ al medio, la mayoría de las procedencias de Salix originaron 1 a 3 brotes delgados y poco vigorosos en un período de 4-5 semanas. Este resultado influyó negativamente en la supervivencia de las plantas al momento de su aclimatación. Sin embargo, este tratamiento hormonal fue óptimo para un $24 \%$ de las procedencias (Cuadro 3), las cuales lograron brotes más vigorosos comparados con los otros 2 tratamientos.

Si bien el $\mathrm{GA}_{3}$ no ha sido muy utilizado en los trabajos de micropropagación de Salix spp., se sabe que estimula el desarrollo vegetativo, pues permite la elongación y crecimiento de tallos (Nikell, 1991). Al respecto, Ihrig y Beiderbeck (1995), describen el desarrollo de delgados brotes foliares en $\boldsymbol{S}$. alba cuando es micropropagada en presencia de $\mathrm{GA}_{3}$, lo cual es muy similar a nuestros resultados.

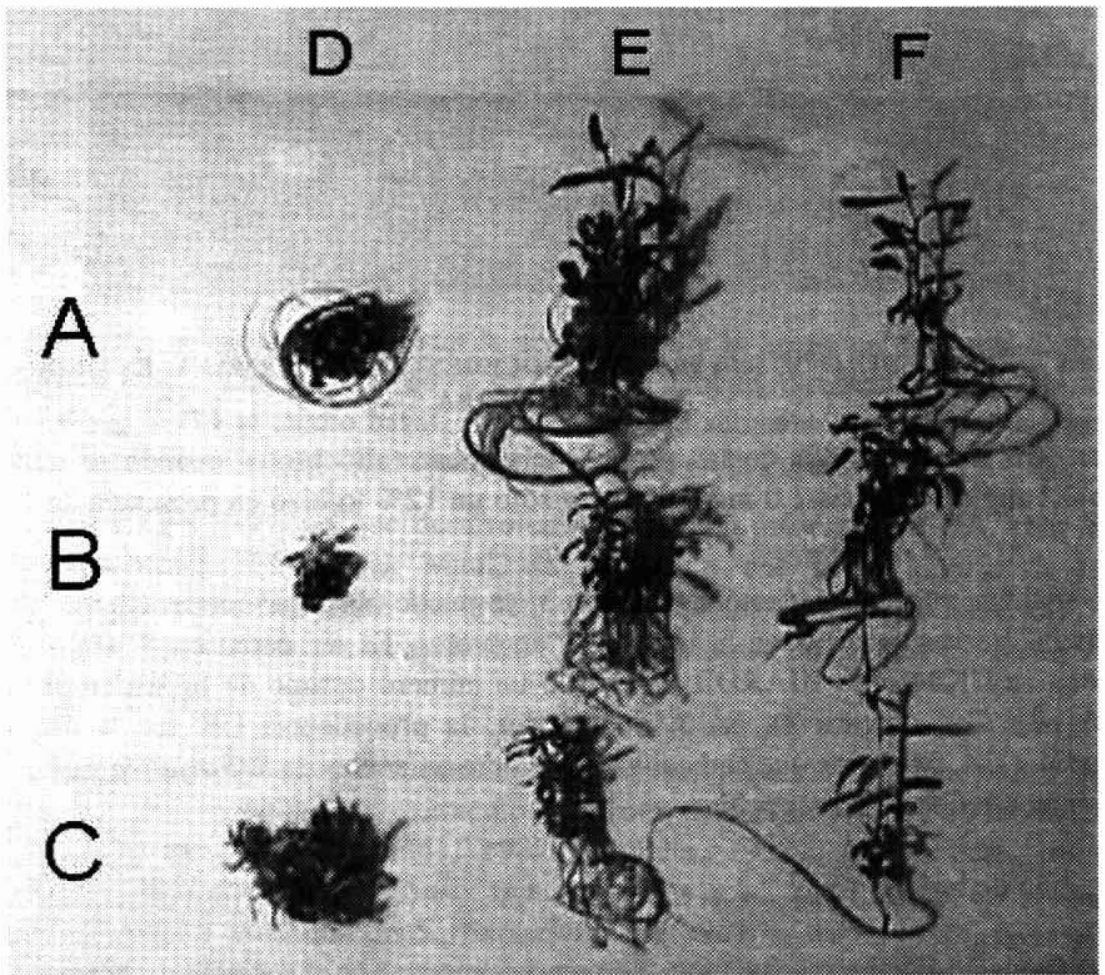

Figura 2. EFECTO DE 3 TRATAMIENTOS HORMONALES SOBRE EL DESARROLLO DE 3 PROCEDENCIAS DE Salix spp.: A= Salix burjatica (UK GERMANY) ; B=Salix viminalis (UK 445 DE BIARDII); C= Salix viminalis (UK MULATIN); D= MS + 0,1 MG DE BA; E = MS + 1,0 MG DE GA + 0,1 MG DE BA; F = MS + 1,0 MG DE GA3. 
La elongación de brotes fue óptima para la mayoría de las procedencias cuando ambas hormonas se aplicaron al medio basal. En estas condiciones, un $76 \%$ de las procedencias mostraron brotes más vigorosos comparados con los otros tratamientos (Cuadro 3; Figura 3).

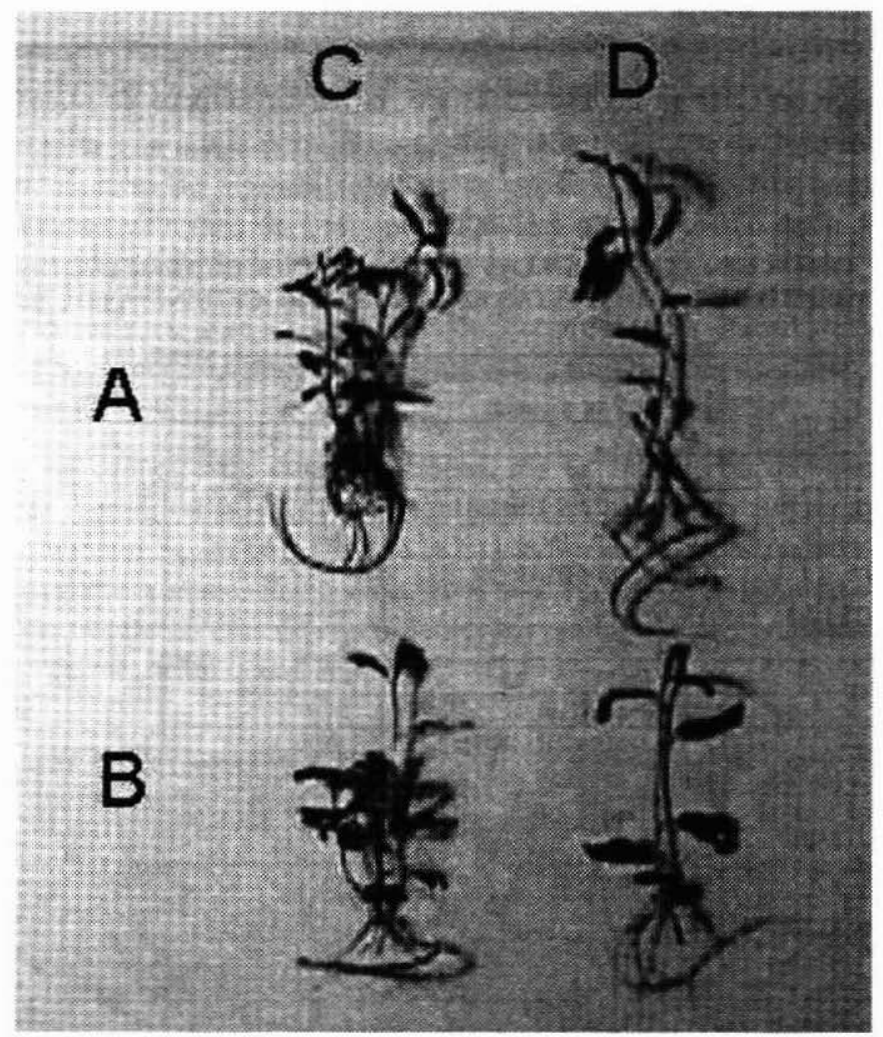

Figura 3. EFECTO DE 2 TRATAMIENTOS HORMONALES SOBRE EL DESARROLLO DE 2 PROCEDENCIAS DE Salix spp.: A= Salix burjatica (UK KORSO) ; B= Salix dasyclados (SWE 77056); C= MS + 1,0 MG DE GA + + 0,1 MG DE BA; D= MS + 1,0 MG DE GA 3 .

Desarrollo de Raíces

La inducción de raíces se logró sin la presencia de auxinas, ocurriendo en forma paralela al crecimiento de los brotes del explante $\mathrm{e}$ independiente de la hormona utilizada en el medio.

Cuando se aplicó BA como único suplemento hormonal, algunas procedencias formaron raíces, a pesar que esta hormona ha sido asociada con la inhibición del 
desarrollo radicular (Bergman et al, 1992; Ahuja, 1987). Es así como, en S. stipularis, $S$. triandra y en algunas de las procedencias de $S$. viminalis y $S$. burjatica se observó un número inferior a 5 raíces por explante, mientras que en las demás procedencias su proliferación fue escasa o nula. El uso de $\mathrm{GA}_{3}$ favoreció el desarrollo de raíces en todas las procedencias, no obstante el crecimiento de éstas, asociadas a un buen desarrollo de la parte aérea, sólo se dio en 6 procedencias (Cuadro 3).

Como se puede apreciar en las Figuras 2 y 3, el mayor número de raíces se observó cuando $\mathrm{GA}_{3}$ más $\mathrm{BA}$ fueron aplicadas al medio.

\section{Cuadro 3.}

\section{MEDIOS ÓPTIMOS UTILIZADOS EN LAS ETAPAS DE INDUCCIÓN, ELONGACIÓN Y ENRAIZAMIENTO DE LAS DISTINTAS ESPECIES Y PROCEDENCIAS DE Salix spp.}

\begin{tabular}{|c|c|c|c|c|c|c|c|}
\hline \multirow[t]{2}{*}{ Especies } & \multirow[t]{2}{*}{$\begin{array}{l}\text { Identificación de las } \\
\text { Procedencias }\end{array}$} & \multicolumn{3}{|c|}{ Inducción } & \multicolumn{3}{|c|}{$\begin{array}{l}\text { Elongación y } \\
\text { Enraizamiento }\end{array}$} \\
\hline & & a & b & c & a & b & c \\
\hline S.stipularis(hib) & UK & + & & & & + & \\
\hline Salix viminalis & UK BOWLES HIBRID & + & & & & & + \\
\hline Salix viminalis & UK MULATIN & + & & & & & + \\
\hline Salix viminalis & UK 445 DE BIARDII & & + & & & & + \\
\hline Salix viminalis & SWE 78183 & + & & & & + & \\
\hline Salix viminalis & SWE 79046 & + & & & & + & \\
\hline Salix viminalis & SWE 78112 & + & & & & + & \\
\hline Salix triandra & UK Black Maul & + & & & & + & \\
\hline Salix purpurea & CAN ONTARIO PUR 12 & & + & & & + & \\
\hline Hibrido China shrub & CAN. ONTARIO S-67 & + & & & & + & \\
\hline Hibrido Belgicum Red & HOLANDA & + & & & & + & \\
\hline Salix dasyclados & UK & + & & & & + & \\
\hline Salix dasyclados & SWE 77056 & & + & & & + & \\
\hline Salix dasyclados & SWE 79097 & & + & & & + & \\
\hline Salix dasyclados & SWE 81090 & & + & & & + & \\
\hline Salix burjatica & UK KORSO & & + & & & + & \\
\hline Salix burjatica & UK GERMANY & + & & & & + & \\
\hline Salix burjatica & UK-83 & & & + & & & + \\
\hline Salix calodendron & UK & & + & & & + & \\
\hline Salix sericans & UK COLES & + & & & & + & \\
\hline Salix sericans & UK REIFENWEIDE & + & & & & + & \\
\hline Salix eriocephala & CAN.ONTARIO 558 & + & & & & + & \\
\hline Salix eriocephala & CAN. ONTARIO ER63 & + & & & & + & \\
\hline S.eriocephalax pentandra & CAN. ONTARIO 601 & & & + & & & + \\
\hline S.eriocephala $x$ exigua & CAN. ONTARIO 611 & & & + & & & + \\
\hline Porcentaje & & 60 & 28 & 12 & 0 & 76 & 24 \\
\hline
\end{tabular}

Nota : $a=M S+0,1 \mathrm{mg}$ de $\mathrm{BA} ; \mathrm{b}=\mathrm{MS}+0,1 \mathrm{mg}$ de $\mathrm{BA}+1,0 \mathrm{mg}$ de $\mathrm{GA}_{3} ; \mathrm{c}=\mathrm{MS}+1,0 \mathrm{mg}$ de $\mathrm{GA}_{3}$

Finalmente, es necesario señalar que durante la etapa de elongación de brotes y enraizamiento, el tratamiento hormonal óptimo fue aquel que permitió obtener explantes 
con un desarrollo más equilibrado entre la parte aérea y radicular, lo cual facilitó su posterior aclimatación.

\section{Aclimatación}

Durante el proceso de aclimatación se evaluaron 3 tipos de sustratos: vermiculita, arena, y combinación de arena con mezcla Sunshine.

La vermiculita y la arena permitieron inicialmente un buen desarrollo de las plantas. Sin embargo, al cabo de algunas semanas se produjo una elevada mortalidad ( $>50 \%$ ) debido a una excesiva retención de humedad, deficiente desarrollo de la masa radicular y una elevada proliferación de hongos.

Se pudo determinar que la combinación de arena más mezcla Sunshine dio los mejores resultados, por lo tanto, este sustrato se siguió utilizando durante toda la etapa de aclimatación.

Tomando en cuenta estas consideraciones, los explantes con un buen desarrollo de follaje y raíces fueron transplantados a cajas de plástico con aproximadamente $3.300 \mathrm{~cm}^{3}$ de sustrato húmedo y estéril (Figura 4). Las cajas fueron selladas con plástico (alusaplast) por una semana, luego de lo cual se comenzó la aplicación de fertilizante y fungicida. Después de 10 días de crecimiento, las plantas fueron gradualmente expuestas a condiciones de menor humedad relativa.

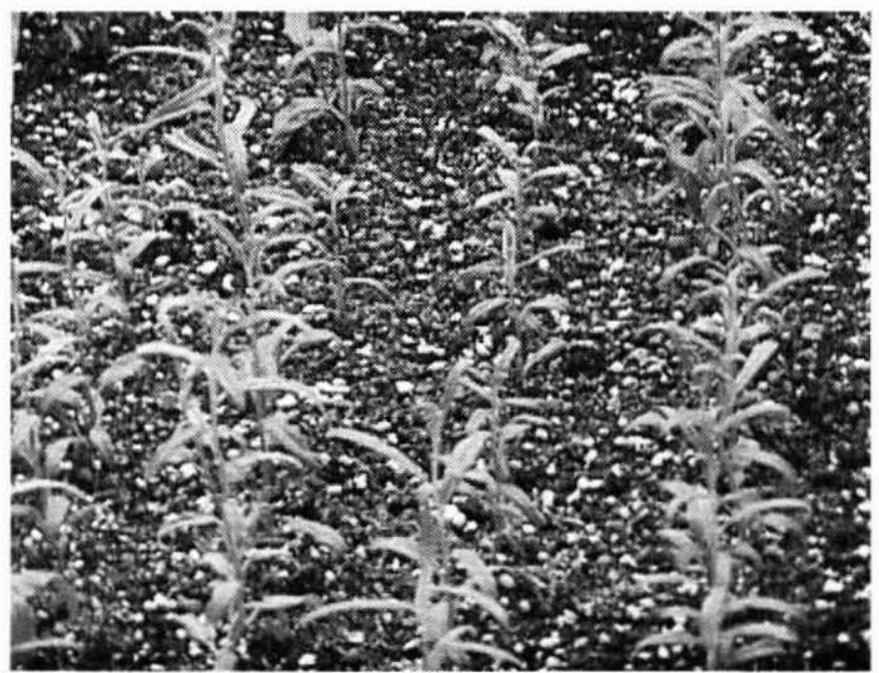

Figura 4. PLANTAS DE Salix stipularis (HIB), PROCEDENCIA UK, CRECIENDO EN ARENA MAS MEZCLA SUNSHINE (1:1) 
Es importante señalar que durante la aclimatación es crítico regular el tiempo de exposición de las plantas a las condiciones ambientales externas, para así evitar la elevada mortalidad que se produce durante esta etapa. Ella se debería, principalmente, a las anormalidades morfológicas que presentan las plantas cultivadas in vitro, tales como la ausencia de cutícula cerosa, reducido número de tricomas y estomas constantemente abiertos. En estas condiciones, las plantas mantienen una elevada tasa de evapotranspiración, por lo tanto, si no se manejan adecuadamente las condiciones de humedad relativa, se produce una excesiva mortalidad por efecto de la deshidratación (Donnelly y Tisdall, 1993). Según Driver y Suttle (1987) y Donelly y Tisdall (1993) las plantas deben ser gradualmente expuestas a condiciones de menor humedad.

De acuerdo a los resultados obtenidos en este estudio, la mejor estrategia de aclimatación ( $>80 \%$ de supervivencia) fue acondicionar las plantas lentamente, durante 45 días. En el transcurso de este período, las plantas fueron expuestas al medio externo por $20 \mathrm{~min}, 2 \mathrm{~h}, 5 \mathrm{~h}$ y $10 \mathrm{~h}$ durante la primera, segunda, tercera y cuarta semana respectivamente, dejándolas definitivamente expuestas al medio externo por el resto del tiempo.

Finalmente, las plantas aclimatadas fueron transplantadas a bolsas individuales con una mezcla en partes iguales de corteza de pino y arena (Figura 5), y luego fueron llevadas a invernadero para continuar con su crecimiento y endurecimiento.

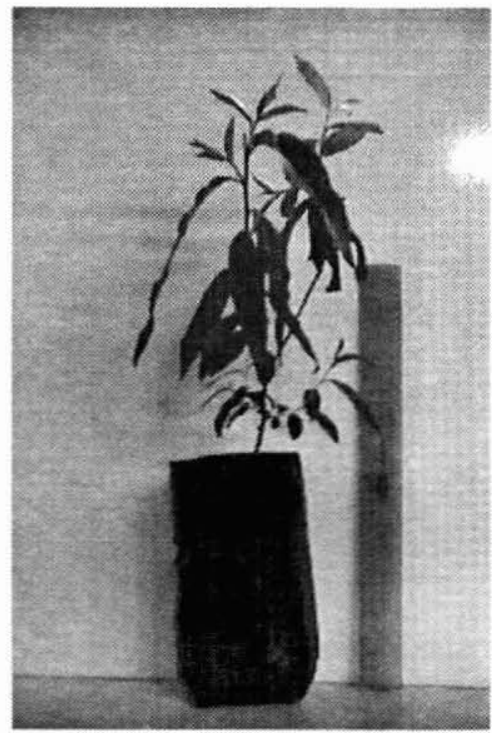

Figura 5. PLANTAS DE Salix sericans PROCEDENCIA UK COLES, CRECIENDO EN ARENA MÁS CORTEZA DE PINO (1:1). 


\section{Condiciones Fitosanitarias}

Durante la etapa de multiplicación in vitro, se apreció aproximadamente un $3 \%$ de mortalidad debido a contaminación por bacterias y hongos de los géneros Penicillium, Botritis y Aspergillus.

En el proceso de aclimatación, el ataque por hongos fue otro factor importante que generó pérdida de plantas ( $>50 \%$ ). Por lo tanto, como una medida preventiva, durante todo este proceso se aplicó fungicida (Benlate $200 \mathrm{mg} / \mathrm{tt}$ y/o Captan $200 \mathrm{mg} / \mathrm{lt}$ ), 2 veces por semana, reduciendo la mortalidad a menos de un $10 \%$. Además, para favorecer un mayor crecimiento de las plantas se realizaron fertilizaciones foliares semanales con medio MS al $50 \%$.

En el transcurso de las etapas de multiplicación, aclimatación y crecimiento en invernadero, el Servicio Agrícola y Ganadero (SAG) verificó la ausencia del hongo cuarentenario Diplodina microsperma, por lo cual las plantas fueron liberadas de la cuarentena fitosanitaria.

\section{CONCLUSIONES}

La desinfección del material vegetal con fungicidas e hipoclorito de sodio permitió mantener una baja incidencia de agentes fitopatógenos y la eliminación total del hongo cuarentenario Diplodina microsperma.

El uso del medio MS dio muy buenos resultados para las 25 procedencias de Salix spp. Sin embargo, se observaron algunas diferencias intra e interespecíficas en la inducción de brotes, elongación y enraizamiento de los explantes según el tratamiento hormonal aplicado.

Un $60 \%$ de las procedencias indujo brotes cuando se aplicó $0,1 \mathrm{mg}$ de $\mathrm{BA}$ al medio. Mientras que para un $28 \%$ y $12 \%$ de las procedencias los resultados fueron óptimos al utilizar $0,1 \mathrm{mg}$ de $\mathrm{BA}+1,0 \mathrm{mg}$ de $\mathrm{GA}_{3}$ y $1,0 \mathrm{mg}$ de $\mathrm{GA}_{3}$, respectivamente.

En la etapa de elongación, la aplicación de $0,1 \mathrm{mg}$ de $\mathrm{BA}+1,0 \mathrm{mg}$ de $\mathrm{GA}_{3}$ permitió un desarrollo rápido y vigoroso de un $76 \%$ de las procedencias (más de 1 brote por explante). Las restantes procedencias (24\%) presentaron un mejor crecimiento cuando se utilizó 1,0 mg de $\mathrm{GA}_{3}$ en el medio, pero a diferencia del anterior tratamiento, la mayoría de los explantes elongaron un solo brote.

La formación de raíces se obtuvo sin el empleo de auxinas y fue paralela al crecimiento aéreo de los explantes. Si bien la aplicación de BA generó raíces y un gran número de brotes en la mayoría de las procedencias, su lento desarrollo aéreo limitó severamente su éxito en la etapa de aclimatación. En términos generales, el tratamiento hormonal empleado para la elongación de brotes fue utilizado a su vez para generar un adecuado crecimiento radicular. 
Una etapa crítica en el proceso de micropropagación de Salix spp. fue la aclimatación, donde tuvieron especial importancia el tipo de sustrato utilizado y la estrategia de acondicionamiento al medio externo.

$\mathrm{Al}$ respecto, el uso en partes iguales de arena de Lampa y una mezcla comercial de turba (Sunshine) mostró ser un sustrato poroso y liviano, que permitió un adecuado crecimiento de las plantas. La estrategia de acondicionamiento fue llevada a cabo a través de la exposición gradual del material vegetal al ambiente externo. En estas condiciones se obtuvo una sobrevivencia mayor al $80 \%$.

Sin lugar a dudas, el material aséptico producido mediante el cultivo in vitro es el método más eficiente para importar material vegetal libre de organismos fitopatógenos. No obstante, el ingreso de plantas o segmentos sin la incorporación de esta tecnología es riesgosa por la posible contaminación del material ingresado. En tales circunstancias, nuestro país tiene la obligación de aplicar los mecanismos de resguardo correspondientes, como es la cuarentena fitosanitaria. Esta medida impide el uso inmediato de este material hasta el levantamiento de la cuarentena. Si durante este período, se detecta la presencia de algún organismo patógeno cuarentenario, el material tiene que ser completamente eliminado.

Sin embargo, como ha quedado demostrado en este estudio, la utilización del cultivo in vitro permite el rescate de material valioso, eliminando en forma rápida y eficiente la presencia de organismos patógenos. Además, el trabajo es desarrollado en un mínimo espacio, obteniéndose plantas en forma constante durante todo el año. Por lo tanto, esta metodología podría aplicarse a situaciones similares, especialmente cuando el material vegetal es muy valioso y no exista otra alternativa capaz de rescatarlo en un corto lapso de tiempo.

\section{BIBLIOGRAFÍA}

Ahuja, M.R. 1987. In vitro propagation of poplar and aspen. 207-22p. In: Bonga, J.M. y Durzan, D.J. (eds.). Cell and tissue culture in forestry. Case histories: Gymnosperms, Angiosperms and Palms V3. Martinus Nijhoff Publishers, Dordrecht, Netherlands.

Agrawal, DC y Gebhardt, K. 1994. Rapid micropropagation of hybrid willow (Salix) established by ovary culture. Journal-of-Plant-Physiology. 143( 6):763-765.

Bergman, L; Arnold, S y Erikson, T. 1984. Culture of Salix species in vitro.

Rapport,-Avdelningen-for-Energiskogsodling,-Institutionen-for-Ekologi-och-Miljovard,-SverigesLantbruksuniversitet. No. 36, 26 pp.

Bergman, L. ; Arnold, S y Erickson, T. 1992. Culture of Salix species in vitro. 28p. In: Hall, D. O.; Grassi, G. y Scheer, H. (eds.). Proceedings of $7^{\text {th }}$ International Conference on Biomass for Energy and Industry, 5-9 October. Florence, Italy.

Bhojwani, S.S. 1980. Micropropagation method for a hybrid willow (Salix matsudanaXalba NZ1002). New Zealand Journal of Botany18: 215-220. 
Dhawan, V. 1993. Micropropagation of nitrogen-fixing trees. 303-315p.In: Ahuja, M.R. (ed.).Micropropagation of woody plants (Forest science v.41). Kluwer academic publisher, Dordrecht, Netherlands.

Donnelly, D. y Tisdall, L. 1993. Acclimatization strategies for micropropagated plants. 153-166p. In: Ahuja, M.R. (ed.).Micropropagation of woody plants (Forest science v.41). Kluwer academic publisher, Dordrecht, Netherlands.

Driver, J. A y Suttle, G.R.L. 1987. Nursery handling of propagules.320-335p.In: Bonga, J.M. y Durzan, D.J. (eds.). Cell and tissue culture in forestry. Specific principles and methods: growth and developments. V2. Martinus Nijhoff Publishers, Dordrecht, Netherlands.

Espejo, J.; Arce, P. y Rojas P. 1990. Perspectivas del uso de la micropropagación en la silvicultura. Chile Forestal, Documento Técnico $n^{\circ} 44.7 p$.

Gaspar, Th.; Kevers, C.; Debergh, P.; Maene, L.; Paques, M. y Boxus Ph. 1987. Vitrification: morphological, physiological and ecological aspects.152-166p. In: Bonga, J.M. y Durzan, D.J. (eds.). General principles and biotechnology. V1. Martinus Nijhoff Publishers, Dordrecht, Netherlands.

Ihrig, D. y Beiderbeck, R. 1995. In vitro culture of 'Wirrzopf' tissue of Salix alba L. Journal-ofPlant-Physiology 145: 1-2:178-180.

Minicha, S.C. 1987. Plant growth regulators and morphogenesis in cell and tissue culture of forest trees. 50-66p. In: Bonga, J.M. y Durzan, D.J. (eds.). Cell and tissue culture in forestry. General principles and biotechnology. V1. Martinus Nijhoff Publishers, Dordrecht, Netherlands.

Murashige,T. y Skoog, F. 1962. A revised medium for rapid growth and biossays with tabacco tissue cultures. Physiol. Plant. 15: 473-497.

Nickell, L. 1991. Use of growth regulating chemical.467-487p. In: Raghavendra, A.S. (de.). Physiology of Trees. John Wyley and Sons, Inc., New York.

Pope, D.P.; Brock, J.H. y Backhaus, R.A. 1990. Vegetative propagation of key southwestern woody riparian species. Desert-Plants 10(2): 91-95.

Stoehr, M.U.; Cai, M. y Zsuffa, L. 1989. In vitro plant regeneration via callus culture of mature Salix exigua. Can. J.For. Res. 19:1634-1638.

Winton, LL. 1968. Plantlet formation from aspen tissue culture. Science $160: 1234-1235$.

Wolter, J. 1970. Root and initiation in aspen callus cultures. Science 219:509-510. 